\title{
Could Medieval Medicine Help the Fight Against Antimicrobial Resistance?
}

\begin{abstract}
The emergence of antibiotic-resistant bacteria, combined with a severely stalled discovery pipeline for new antibiotics being developed, has the potential to undo the advances in infection control achieved in the last century. One way around this impasse might be to re-explore the medicinal practices of the medieval world. Why? This is because although the medieval world was ignorant of so much of modern theory, it seems that centuries of practice by medieval doctors could have produced some treatments for infections that were effective. These could contain antimicrobial compounds suitable for development into antibiotics. Our interdisciplinary team, initially based at the University of Nottingham, tested an eyesalve described in the tenth century Anglo-Saxon 'Bald's Leechbook' with startling results. By following the recipe as closely as possible, we created a cocktail that can kill one of the most common causes of eye infections, the bacterium Staphylococcus aureus. More significantly, Bald's eyesalve can kill a range of antibiotic-resistant bacteria. This chapter details our team's initial findings and places them in the context of an interdisciplinary analysis of how medieval doctors used the materia medica available to them. We present novel results confirming the reliability of Bald's eyesalve as an anti-Staphylococcal agent. Further, we demonstrate the potential of 'big data' approaches to turn medical texts into predictive databases for selecting natural materials for antibiotic testing. Finally, we present our work as an example of how interdisciplinary dialogue can significantly advance scholarship.
\end{abstract}

Keywords: medieval medicine, antimicrobial resistance, AMR, interdisciplinary

\section{The Past and Present of Infectious Disease}

Chronic infections are often multi-antibiotic resistant, expensive to manage and can be lethal. Soft tissue infections (e. g. surgical wounds, pressure sores or diabetic ulcers) can be particularly problematic, persisting for months or years. Major contributing pathogens include the so-called ESKAPE bacteria (Enterococcus faecium, Staphylococcus aureus, Klebsiella pneumoniae, Acinetobacter baumannii, Pseudomonas aeruginosa, Enterobacter spp.), which can co-colonize soft tissue to

\footnotetext{
Freya Harrison, School of Life Sciences, Gibbet Hill Campus, University of Warwick, Coventry, CV4 7AL, United Kingdom, f.harrison@warwick.ac.uk

Erin Connelly, Schoenberg Institute for Manuscript Studies, University of Pennsylvania, Philadelphia, PA, 19104, United States, erincon@upenn.edu
} 
form multicellular biofilm: communities of bacteria protected by a sticky slime layer that protects against immune clearance and antibiotic penetration. ${ }^{1}$ Further, antibiotic over-use has led to bacteria evolving genetic strategies to become resistant to the drugs in our armoury. The problem of recalcitrant chronic infection will likely worsen due to a scarcity of new antibiotics in development. ${ }^{2}$

An innovative pipeline for discovering new antimicrobials could have its roots in ethnopharmacology. Pre-modern European medical texts contain abundant remedies for soft tissue (wound, eye and skin) infections, and use many ingredients shown to possess antimicrobial qualities in in vitro tests. These include garlic and other Allium species, ${ }^{3}$ other native plants, ${ }^{4}$ honey, ${ }^{5}$ breast milk, ${ }^{6}$ and metals. ${ }^{7}$ A few of these individual materials have been developed into clinically-useful products (e. g. medical-grade honey), but individual materials generally fail to deliver positive results in clinical trials. ${ }^{8}$

Unlike modern drugs containing a single active ingredient, medieval remedies are typically complex preparations of several ingredients. This could be crucial for producing antimicrobial activity. If this is the case, then this would strongly suggest an element of 'rational drug design' on the part of medieval doctors. It would also

1 Jack N. Pendleton / Sean P. Gorman / Brendan F. Gilmore, Clinical Relevance of the ESKAPE Pathogens, in: Expert Review of Anti-Infective Therapy 11 (2013), pp. 297-308; Francesca L. SHORT / Sarah L. Murdoch / Robert Patrick RYAN, Polybacterial Human Disease. The Ills of Social Networking, in: Trends in Microbiology 22 (2014), pp. 508-516.

2 The Review on Antimicrobial Resistance, Antimicrobial Resistance. Tackling a Crisis for the Health and Wealth of Nations (2014), online: https://amr-review.org (last accessed 15/05/2019).

3 Virginia LAnzotTi / Felice Scala / Giuliano Bonanomi, What Makes Allium Species Effective Against Pathogenic Microbes?, in: Phytochemistry Reviews 12 (2013), pp. 751-772.

4 Frances WATKINS / Barbara PENDRY / Olivia CoRCoran / Alberto SANCHEZ-MEdinA, Anglo-Saxon Pharmacopoeia Revisited. A Potential Treasure in Drug Discovery, in: Drug Discovery Today 16 (2011), pp. 1069-1075; Frances WATKInS / Barbara PENDRY / Alberto SANCHEZ-MEdinA / Olivia CoRCoRAN, Antimicrobial Assays of Three Native British Plants Used in Anglo-Saxon Medicine for Wound Healing Formulations in 10th Century England, in: Journal of Ethnopharmacology 144 (2012), pp. 408-415.

5 Peter C. Molan, Potential of Honey in the Treatment of Wounds and Burns, in: American Journal of Clinical Dermatology 2 (2001), pp. 13-19.

6 Kyle H. Ramsey / Christoffer E. Poulsen / Peter P. Motiu, The in vitro Antimicrobial Capacity of Human Colostrum against Chlamydia trachomatis, in: Journal of Reproductive Immunology 38 (1998), pp. $155-167$.

7 Gregor GRASS / Christopher RENSING / Marc Solioz, Metallic Copper as an Antimicrobial Surface, in: Applied and Environmental Microbiology 77 (2011), pp. 1541-1547; Svitlana CHERNOUSOVA Matthias EPPLE, Silver as Antibacterial Agent: Ion, Nanoparticle, and Metal, in: Angewandte Chemie. International Edition 52 (2013), pp. 1636-1653.

8 E. g. garlic: Alan Robert SMYTH / Paramita M. CifELli / Catharina A. ORTORI / Karima RighETTI / Sarah N. LEWIS / Penny ERSKine / Elaine D. Holland / Michael C. GivsKov / Paul Williams / Miguel CÁmara / David A. BARRETT / Alan J. Knox, Garlic as an Inhibitor of Pseudomonas aeruginosa Quorum Sensing in Cystic Fibrosis - a Pilot Randomized Controlled Trial, in: Pediatric Pulmonology 45 (2010), pp. 356-362. 
mean that tests of individual medical materials are limited in their power to reveal any useful biological effects of medieval remedies. Experiments that test the activities of entire remedies could reveal molecular cocktails with real clinical potential, but these are few and far between. ${ }^{9}$ If medieval cures can kill pathogens, and if this activity relies on the combined action of several compounds, this could make it harder for bacteria to evolve resistance and so produce unusually robust antibiotics. ${ }^{10}$ As well as bactericidal compounds, medieval remedies could yield compounds that make infections less virulent, or more susceptible to treatment with standard antibiotics. Garlic, for example, may reduce tissue damage caused by $P$. aeruginos $a$ and enhance the ability of antibiotics to clear P. aeruginosa infections in mice. ${ }^{11}$ Additionally, extracts from Plantago major leaves (a traditional herbal treatment) may have a significant synergistic effect when combined with the antibiotic gentamicin and applied against $P$. aeruginosa, $S$. aureus and other bacteria. ${ }^{12}$

We and our colleagues in the Ancientbiotics consortium - an international team of researchers based in the arts, humanities and sciences - have instigated a project to explore how medieval Europeans perceived, described and treated infection. In a pilot study, we found that an Anglo-Saxon remedy for bacterial eye infections can kill a range of ESKAPE pathogens, including antibiotic-resistant clinical isolates, in synthetic wounds and an animal model. The remedy's efficacy depends on preparing and combining ingredients as specified in the text. ${ }^{13}$ This could explain why in vitro antibacterial activity of individual ingredients (e. g. garlic) does not reliably translate into clinical potential. ${ }^{14}$ Antibiotic activity may rely on a cocktail of bioactive molecules and/ or on chemical reactions that take place during preparation. This result represents a paradigm shift about medieval medicine, which has - with very few

9 For a rare example, see Barbara BRENnESSEL / Michael D. C. Drout / Robyn Gravel, A Reassessment of the Efficacy of Anglo-Saxon Medicine, in: Anglo-Saxon England 34 (2005), pp. 183-195.

10 Tobias Bollenbach, Antimicrobial Interactions: Mechanisms and Implications for Drug Discovery and Resistance Evolution, in: Current Opinion in Microbiology 27 (2015), pp. 1-9.

11 Thomas Bjarnsholt / Peter Østrup Jensen / Thomas Bovbjerg Rasmussen / Lars Jackie Christophersen / Henrik CAlum / Morten Hentzer / Hans-Petter Hougen / Jørgen RygaARd / Claus Moser / Leo Eberl / Niels Høiby / Michael Christian GivsKov, Garlic Blocks Quorum Sensing and Promotes Rapid Clearing of Pulmonary Pseudomonas aeruginosa Infections, in: Microbiology 151 (2005), pp. 3873-3880.

12 Saffidine KARIMA / Sahli FARIDA / Zerroug Mohamed MiHoub, Antioxidant and Antimicrobial Activities of Plantago major, in: International Journal of Pharmacy and Pharmaceutical Sciences 7 (2015), pp. 58-64.

13 Freya Harrison / Aled E. L. ROBERTs / Rebecca GABriLsKa / Kendra P. Rumbaugh / Christina LeE / Stephen P. Diggle, A 1,000-Year-Old Antimicrobial Remedy with Antistaphylococcal Activity, in: mBio 6 (2015), e01129-01115.

14 Sмүтн et al. (note 8). 
exceptions - been dismissed as superstition or placebo. ${ }^{15}$ Our results suggest that targeted exploration of the medieval pharmacopeia could suggest a wealth of possibilities for developing new antimicrobials.

In this chapter, we will discuss our team's qualitative and quantitative analysis of medieval texts, with the aim of exploring patterns of material usage which may reflect the construction of effective cocktails. Focussed datamining of medieval medical texts, informed by historical/cultural understanding, modern microbiological and pharmacological knowledge, and techniques for analysing information within the texts, could open a new pipeline for the discovery of desperately-needed antibiotics. The ethnopharmacology of Europe has been understudied relative to that of other continents, so potentially useful compounds could lie hidden within the medieval pharmacopeia. We conclude our chapter by venturing some suggestions for smoothing the way towards successful and impactful research across the traditional arts/sciences divide.

\section{Approaches to Studying Medieval Infectious Disease}

Infectious diseases are constant companions of human populations. Throughout history, people have contended with a range of acute and chronic infections, as evidenced by the survival of numerous medical texts and bioarchaeological evidence. ${ }^{16}$ These include specialized human pathogens that are transmitted from person to person; pathogens that normally infect livestock or wild animals but which can occasionally make the jump into humans (zoonoses); or so-called opportunistic pathogens which normally live in soil, water, or as commensals on and in the human body, but can switch to a pathogenic lifestyle if they encounter a human host whose normal immune defences are compromized (for example, by an open wound or severe burn). In trying to understand the social and medical history of infectious disease in the medieval period, we can define two general categories of research question.

First, we can ask questions about aetiology and epidemiology. Which microbes caused problems for medieval people? Were these the same species that continue to cause important health problems today, or were there differences? For example, it is

15 Peregrine HoRDEN, What's Wrong with Early Medieval Medicine?, in: Social History of Medicine 24 (2000), pp. 2-25; Audrey L. MEANEY, The Practice of Medicine in England about the Year 1000, in: Social History of Medicine 13 (2000), pp. 221-237; BRENNESSEL / Drout / GRAVEL (note 9).

16 See, for instance, Charlotte A. ROBERTS / Francisca Alves CARDOSO / K. BERNOFSKY / Charlotte Yvette Henderson / Tina JaKob / K. Plomp / Paola Ponce / Jennifer Sharman / R. SPencer, Palaeopathology: Studying the Origin, Evolution and Frequency of Disease in Human Remains from Archaeological Sites, in: UNESCO Encyclopedia Life Support Systems (online) (2012), https:// www.eolss.net/Sample-Chapters/C04/E6-59-51.pdf (last accessed 15/05/2019). 
possible that medieval people experienced higher levels of zoonoses than their modern descendants because they tended to live in closer association with livestock following the domestication with the introduction of farming in the Neolithic. Second, we can ask questions about how people responded to infection. Were these diseases recognized as being caused by influences external to the body, something perhaps transmissible from one person to another? How did people treat symptoms which we now recognize as microbial infection, and can any of these treatments successfully kill exemplar pathogenic bacteria?

None of these questions is trivial to answer. We must use a range of insights and tools from different disciplines - arts, humanities and sciences - to even begin to dissect the relationships between medieval people and their pathogens.

\subsection{Recognising Medieval Infections}

Aside from a few notable exceptions (leprosy, tertiary syphilis, tuberculosis, and some chronic respiratory tract infections), microbial pathogens generally do not cause diagnostic damage to bones and teeth, and a person would need to develop the chronic stages of infectious disease anyway to develop characteristic bone changes that are recognisable. ${ }^{17}$ Soft tissue lesions, microbial toxins and sepsis are invisible killers when trying to assign causes of death to people solely represented by their skeletal remains. Recent advances in genetic technology have allowed researchers to isolate fragile and fragmented microbial DNA from samples taken from archaeological human remains and determine the genus, species and even infectious strain present, and such studies are becoming more common. Other biomolecular markers of infection available to archaeologists include microbes entombed in dental calculus and structural molecules derived from bacterial cell envelopes. Studies using the combined skills of bioarchaeologists and microbial geneticists have provided insights into the epidemiology of the plague and leprosy, and glimpses into the infection-related deaths of a small number of medieval people. ${ }^{18}$ But

17 Charlotte A. RoBerts, Human Remains in Archaeology. A Handbook (Practical Handbooks in Archaeology 19), York 2012.

18 For plague: Verena J. Schuenemann / Kirsten Bos / Sharon DeWitTE / Sarah Schmedes / Joslyn JAmieson / Alissa MitTniK / Stephen Forrest / Brian K. CoOmbes / James W. Wood / David J. D. EARN / William White / Johannes KrauSE / Hendrik N. PoINAR, Targeted Enrichment of Ancient Pathogens Yielding the $p P C P 1$ Plasmid of Yersinia pestis from Victims of the Black Death, in: Proceedings of the National Academy of Sciences 108 (2011), pp. e746-e752; Marie A. SPYROU / Rezeda I. TukHBATovA / Michal FELdMAN / Joanna DRATH / Sacha KACKI / Julia BELTRÁN DE HEREdIA / Susanna ARNOLD / Airat G. Sitdikov / Dominique CASTEX / Joachim WaHL / Ilgizar R. GAzIMzYAnov / Danis K. NuRgaliev / Alexander Herbig / Kirsten I. Bos / Johannes KRAUSE, Historical Y. pestis Genomes Reveal the European Black Death as the Source of Ancient and Modern Plague Pandemics, in: Cell Host \& Microbe 19 (2016), pp. 874-881; Cheryl P. ANDAM / Colin J. Worby / Qiuzhi Chang / Michael G. Campana, Microbial 
despite these captivating snapshots of past microbial disease, this work is not without challenges and caveats, ${ }^{19}$ and it remains difficult to find physical evidence of identifiable pathogens that infected medieval people.

Textual evidence goes some way to filling this gap. If a medical text describes recognisable symptoms of infection, we can use what we know about the aetiology of those symptoms in the modern world to make an educated guess at the likely causative agents. A recipe for a wen or lump in the eye in the Anglo-Saxon 'Bald's Leechbook' most likely describes a sty: an infection of an eyelash follicle that causes an irritated swelling. Today, most stys are caused by the bacterium $S$. aureus. As this species is a normal inhabitant of the skin and mucous membranes of healthy people, but can break out of this quiescent lifestyle to cause a range of unpleasant infections, it seems sensible to assume that $S$. aureus was also responsible for many stys in medieval times. Similarly, in the modern world many opportunistic infections of wounds are caused by P. aeruginosa: as this species is ubiquitous in natural soils and water sources, it makes sense to assume that medieval people were similarly at risk from colonisation when they had open wounds. By combining expertises of people versed in philology and in microbiology, we can take a qualitative approach to suggesting likely causes of symptoms described in texts.

The nature of medieval recognition of, and responses to, pathogens is a complex area to address and demands a broad-ranging, interdisciplinary approach. Medieval medical texts contain descriptions of diseases that could be considered infectious, but, to fully explore contemporary social and medical perceptions, patterns and processes relating to contagion and disease, we need expertise and input from at least five areas of knowledge:

Genomics of Ancient Plagues and Outbreaks, in: Trends in Microbiology 24 (2016), pp. 978-990. For tuberculosis, see Janet E. REDMAN / Matthew J. SHAW / Anthony I. MalLET / Ana Luisa SANTos / Charlotte A. RoBerTS / Angela M. GERnAEY / David E. MinNIKIN, Mycocerosic Acid Biomarkers for the Diagnosis of Tuberculosis in the Coimbra Skeletal Collection, in: Tuberculosis 89 (2009), pp. 267-990. For leprosy, see Verena J. Schuenemann / C. Avanzi / B. Krause-Kyora / A. Seitz / Alexander Herbig, Ancient Genomes Reveal a High Diversity of Mycobacterium leprae in Medieval Europe, in: PLOS Pathogens 14 (2018), e1006997. For others, see Gemma L. KAY / Martin J. SERGEANT / Valentina GIUfFRA / Pasquale BANDIERA / Marco Milanese / Barbara BRAMANTI / Raffaella BianucCi / Mark J. PALLEN, Recovery of a Medieval Brucella melitensis Genome Using Shotgun Metagenomics, in: mBio 5 (2014), e01337-e01314; Alison M. Devault / Tatum D. MoRTimer / Andrew Kitchen / Henrike KieSEwetTer / Jacob M. EnK / G. Brian Golding / John R. Southon / Melanie Kuch / Ana T. Duggan / William AYlWard / Shea N. GARDNER / Jonathan E. ALLEN / Andrew M. King / Gerard D. WRiGHT / Makoto KuRODA / Kengo Kato / Derek E. G. Briggs / Gino FornaCiari / Edward C. Holmes / Hendrik N. Poinar / Caitlin S. PePPERELL, A Molecular Portrait of Maternal Sepsis from Byzantine Troy, in: eLife 6 (2017), e20983.

19 See e. g. Romy MÜLLER / Charlotte A. ROBERTS / Terence A. BRown, Complications in the Study of Ancient Tuberculosis: Non-specificity of IS6110 PCRs, in: STAR: Science \& Technology of Archaeological Research 1 (2015), pp. 1-8, and Romy MÜLLER / Charlotte A. ROBERTS / Terence A. BRown, Complications in the Study of Ancient Tuberculosis: Presence of Environmental Bacteria in Human Archaeological Remains, in: Journal of Archaeological Science 68 (2016), pp. 5-11. 
- Cultural and social history: to explore perceptions and contexts of disease as people experienced it and as physicians approached it. ${ }^{20}$

- Manuscript studies: to determine how diseases were described in contemporary written sources. These include annals (which tell us about spatiotemporal patterns of endemic and epidemic disease, death tolls and general public perceptions) and medical texts (which give us contemporary descriptions of the symptoms and perceived aetiology of infections, and details of what was prescribed to treat them). ${ }^{21}$

- Microbiology and immunology: to determine which diseases most likely are being described by contemporary observers and suggest the likely causative agents.

- Ethnobotany: to understand which natural medical materials were used and how they were processed. ${ }^{22}$

- Medicinal chemistry: to determine which - if any - biologically active compounds are contained within contemporary materia medica. ${ }^{23}$

Combining these perspectives, and the specialized analytical tools that each specialism can contribute, makes it possible to improve our knowledge of medieval rationality and pre-modern 'science'. This approach also allows us to bring the study of medieval European medicine within the realm of ethnopharmacology.

\section{The Ethnopharmacology of an Anglo-Saxon Infection Remedy}

\subsection{A Potential 'Ancientbiotic' from 'Bald's Leechbook'}

With these questions in mind, our team set about conducting an interdisciplinary study of a remedy from a tenth-century Old English medical text known as 'Bald's

20 See e. g. Sally Crawford / Christina LeE (eds.), Social Dimensions of Medieval Disease and Disability (Studies in Early Medicine 3), Oxford 2014.

21 See e. g. Conor Kostick / Francis LudLow, Subsistence Crises, Mass Mortality, Epidemic Disease and Drought in Early Medieval Europe and the Near East, 750-1000 CE, in: Timothy NEWFIELD (ed.), Mortality Crises Between the Plagues, c. 800-c. 1300 CE, Cambridge (in preparation); Malcom Laurence CAMERon, Anglo-Saxon Medicine, Cambridge 2008; CRAWFord / LEE (note 20).

22 See e. g. Youyou Tu, The Discovery of Artemisinin (Qinghaosu) and Gifts from Chinese Medicine, in: Nature Medicine 17 (2011), pp. 1217-1220, online (DOI): 10.1038/nm.2471 (last accessed 15/05/2019); WATKINS et al. (2011, 2012) (note 4).

23 See e. g. Lanzotti / Scala / Bonanomi (note 3); Watkins / PendRY et al. 2011 and Watkins / PendRY et al. 2012 (note 4); Cassandra L. QuAve / James T. LyLes / Jeffery S. Kavanaugh / Kate Nelson / Corey P. Parlet / Heidi A. Crosby / Kristopher P. Heilmann / Alexander R. HoRswill, Castanea sativa (European Chestnut) Leaf Extracts Rich in Ursene and Oleanene Derivatives Block Staphylococcus aureus Virulence and Pathogenesis without Detectable Resistance, in: PLoS One 10 (2015), e0136486. 
Leechbook'. A colophon states that the text was compiled for an enigmatic figure called Bald. The part of the book that survives to the present day is held by the British Library (London, British Library, Royal MS 12 D XVII) and contains many hundreds of remedies for all manner of ailments. One remedy stands out as particularly interesting to microbiologists (Figure 1A):

Make an eyesalve against a wen: take equal amounts of [an Allium species] and garlic, pound well together, take equal amounts of wine and oxgall, mix with the alliums, put this in a brass vessel, let [the mixture] stand for nine nights in the brass vessel, wring through a cloth and clarify well, put in a horn and at night apply to the eye with a feather; the best medicine. (translation by Christina LEE)

As discussed above, a wen, or lump, in the eye is most likely a sty. But it is the ingredients list that made the microbiologists on our team take notice of this remedy. Allium species are remarkable among plants for the range of antimicrobial compounds they can make. Compounds isolated from garlic, leek, onion and other species within this genus have been shown to kill $S$. aureus and other troublesome bacterial species, to prevent them from sticking themselves together into protective biofilms and to interfere in the cell-cell signalling processes by which bacteria switch to a disease-causing mode. ${ }^{24}$ Bile is a surfactant that can punch holes in the fatty membranes that surround bacteria, and it also triggers human cells to defend themselves against bacterial invaders. ${ }^{25}$ Wine could provide various grape-derived antimicrobial small molecules, or simply act as a solvent to extract useful compounds from the plant tissues in the recipe. Finally, antimicrobial copper salts from the brass/bronze vessel could leach into the salve. ${ }^{26}$

Could this apparently multi-pronged attack on bacteria inside the wen really be "the best medicine"? An earlier study by BRENNESSEL, DROUT and GRAVEL concluded that the promise of the recipe was not borne out by its performance in laboratory tests, ${ }^{27}$ but these authors did not have the microbiological tools and techniques at our disposal. The original authors made their eyesalve, saturated small pieces of filter paper with the resulting liquid, placed these on petri dishes spread with bacteria, and then incubated the dishes to see if bacterial growth was inhibited in the vicinity of the filter paper. This is a standard method of

24 LANZOTTI / SCALA / BONANOMI (note 3).

25 Alan F. Hofmann / Lars Eckmann, How Bile Acids Confer Gut Mucosal Protection Against Bacteria, in: Proceedings of the National Academy of Sciences of the United States of America 103 (2006), pp. 4333-4334.

26 Grass / Rensing / Solioz (note 7); Kaveri S. Chaturvedi / Jeffrey P. HendERSon, Pathogenic Adaptations to Host-derived Antibacterial Copper, in: Frontiers in Cellular and Infection Microbiology 4 (2014), online (DOI): 10.3389/fcimb.2014.00003 (last accessed: 15/05/2019). Copper plates have been found associated with bones of skeletons, see note 17.

27 BRENNESSEL / DRout / GRAVEL (note 9). 
(A)

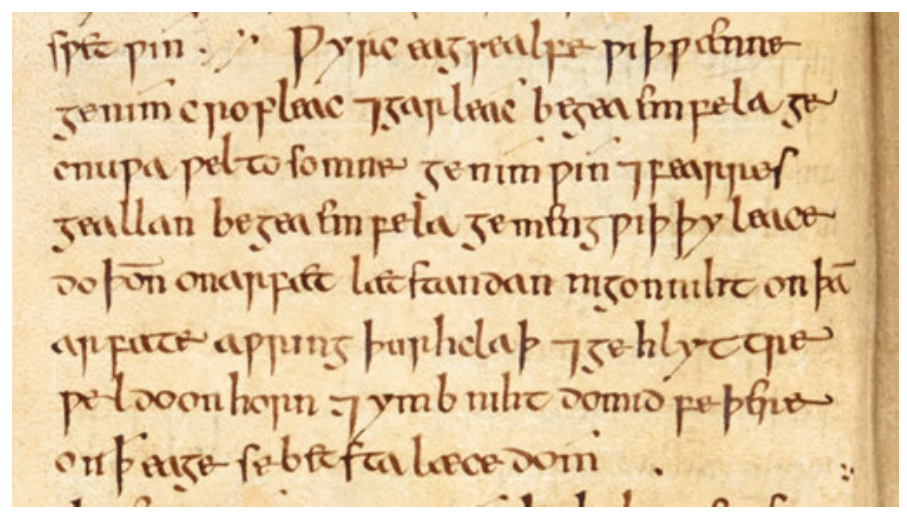

(B)

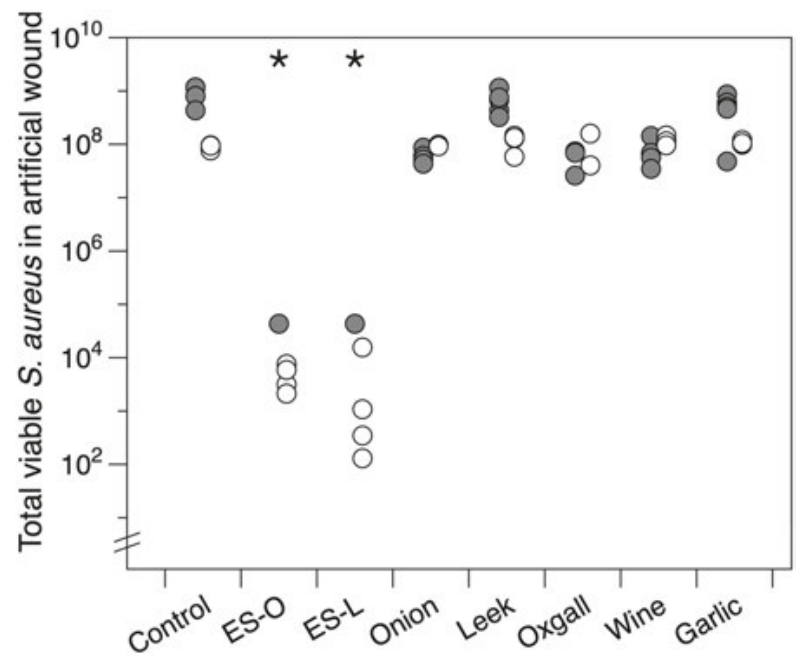

Figure 1: A) Facsimile of a recipe for an eyesalve against a wen, taken from 'Bald's Leechbook' (London, British Library, Royal 12 D XVII) @ The British Library Board, reproduced with permission. B) Two batches of eyesalve were made, using fresh ingredients each time (open and filled circles denote the two batches), with either onion (ES-0) or leek (ES-L) for cropleac. For each batch, two hundred microliters of eyesalve or of each individual ingredient preparation was added to five oneday-old cultures of $S$. aureus growing at $37^{\circ} \mathrm{C}$ in a synthetic wound. After $24 \mathrm{~h}$ of further incubation, the collagen in the synthetic wound was dissolved to recover bacterial cells. The control treatment was sterile distilled water left to stand for nine days in the presence of brass, which was also present in all other preparations, to simulate the presence of a copper alloy vessel. Asterisks denote treatments whose results were statistically significantly different from those of the control. (Reproduced with permission from HARRISON et al. [note 13]). 
testing modern antibiotics against bacteria taken from clinical samples, in order to determine which drugs to administer. But it delivers only a very small volume of the test substance to the bacteria - a few microliters - so it is likely to give false negative results when the concentration of antibacterial compounds present is low, or when they are volatile (i. e. evaporate readily).

We therefore decided to re-test Bald's eyesalve. We made two versions of the salve, using onion and leek respectively for the mysterious Allium species referred to as cropleac. We made our salve in sterile glass bottles, but added small squares of brass to simulate the copper alloy vessel. The first hint that the mixture could be antibacterial came when we attempted to culture bacteria from the mixture after its nine-day resting period. The bacteria initially present on the vegetables did not survive this period of time in the mixture: the salve was self-sterilising. We then grew $S$. aureus in a clinically realistic biofilm model - serum from blood, solidified with collagen to mimic soft tissue - and added drops of Bald's eyesalve to the mature biofilms. We were not prepared for the result: biofilms subjected to a 'mock' treatment (sterile water plus brass, left for nine days), or treated with individual recipe ingredients, contained a few hundred million to a billion live bacteria, but we could only retrieve a few hundred or a few thousand live bacteria from biofilms exposed to either version of the full recipe (Figure 1B).

That a millennium-old remedy could reduce bacterial viability by several orders of magnitude was unprecedented, and sufficiently significant to justify a test in animals. We went on to show that Bald's eyesalve could kill the antibioticresistant 'superbug' strain of $S$. aureus, MRSA, in infected animal tissue. Infected wound tissue was excised from mice, and exposed to the eyesalve for a short length of time ( 4 hours). In this experiment, the antibiotic of last resort against MRSA, vancomycin, kills approximately $50 \%$ of MRSA bacteria in the tissue, but the eyesalve killed approximately $90 \%$. We also verified that in vitro antibacterial activity required all ingredients to be present except for the brass, and was not present if the salve was used immediately after preparation (i. e. without the nineday waiting period). Further, we went on to test numerous batches of the eyesalve, made with fresh ingredients each time, and by different people, and found that the anti-staphylococcal effect in the in vitro model was reproducible. At time of writing, we are collating data on 56 batches of the eyesalve made by 11 different people and an analysis of reproducibility will be presented in a future publication.

We have since shown that Bald's eyesalve can kill a range of ESKAPE bacteria, including antibiotic-resistant clinical isolates, but it does not kill indiscriminately: some bacteria are impervious. ${ }^{28}$ This shows that whatever is present in the eyesalve

28 Freya Harrison / Rebecca GABRILSKa / Sheyda AzImi / Kendra P. Rumbaugh / Christina LeE / Stephen P. DIGgLe, The Potential of Medieval 'Ancientbiotics' in the Treatment of Chronic Biofilm Infection, Annual Conference of the Microbiology Society, Liverpool 2016. 
is not a non-specific biocidal agent. Rather, whatever happens when the various ingredients are combined produces a substance or substances with a specific mode of action to kill certain bacteria. This specificity is one thing that delineates a potential antibiotic from, say, bleach. These results have spurred us on to begin to explore the spectrum of the eyesalve's antibacterial activity (what can it kill?), its mechanism of action (how does it kill?), the pharmacological basis of its action (what active molecules does it contain?), and its likely safety (can it damage human cells?).

A recent publication by another research group attributes the antibacterial efficacy of the eyesalve to the compound allicin, present in garlic. ${ }^{29}$ However, this work addressed only killing of bacteria in planktonic culture and not in biofilms, where increased antibiotic tolerance may require the action of several antibacterial agents at once - and, critically, where garlic alone is not an effective anti-staphylococcal treatment (Figure 1B). Thus, more meticulous explorations are needed. Safety and toxicity testing using cultured human cell lines or live animals are key steps in the early scoping of any potential antibiotic, and the eyesalve ingredients contain a range of compounds that could cause moderate to severe allergic reactions when applied topically. Crushed garlic, in particular, can cause skin reactions ranging from contact dermatitis to chemical burns (partly attributable to allicin), so it is crucial to assess whether the eyesalve carries a safety risk. ${ }^{30}$ Chemically dissecting the eyesalve and carrying out safety testing is a significant undertaking, and we are delighted that the Ancientbiotics consortium has received research funding from Diabetes UK to begin this process. ${ }^{31}$ However, answering these questions fully will require us to work together for the foreseeable future.

Whether Bald's eyesalve could ever be turned into a standardized medicine is something we cannot predict at this moment. However, the fundamental result of our study is the discovery that the cocktail of ingredients in Bald's eyesalve is greater than the sum of its parts. By combining specific materia medica, none of which has significant antibacterial activity when used alone, an active mixture is created. This raises the tantalising suggestion that at least some of the cocktails constructed by medieval doctors were rationally designed (even if the initial stages of discovery relied on trial and error!). If this is true, then it means that a powerful new approach to drug discovery could lie in reconstructing and testing pre-modern

29 Amanda L. Fuchs / Alan J. Weaver, Jr. / Brian P. Tripet / Mary Cloud / B. Ammons / Martin TEINTZE / Valerie Copí,, Characterization of the Antibacterial Activity of Bald's Eyesalve against Drug Resistant Staphylococcus aureus and Pseudomonas aeruginosa, in: PLoS ONE 13 (2018), e020810.

30 Cem Kıvılcım KaÇAR / Ebru Tarıkçı Kiliç/ Hakan AKelma / Osman Uzundere / Ayhan KaYdu / Erhan GöкÇEK, Medical Folk Remedy: Two Cases of Garlic Burns, in: Journal of Burn Care \& Research 40 (2019), pp. 133-135.

31 "Assessing the potential of a medieval antibiotic to treat infected diabetic ulcers." PI: Dr Freya Harrison, University of Warwick. The Project runs from 2018-2020. 
remedies, rather than simply exploring individual traditional medical materials for potential activity. Our results suggest that to discount the antibacterial potential of individual traditional medical materials because they do not have significant clinical potential when used alone would be to throw the baby out with the bathwater. ${ }^{32}$ Perhaps it is to combinations of traditional materia medica that we must look for novel antibacterial treatment.

The results of our work led us to wonder whether Bald's eyesalve was a lucky stab in the dark. Is it the sole useful 'ancientbiotic' among a vast collection of placebos? Or does its existence reflect some empirical medical knowledge and method on the part of medieval physicians, and thus the existence of other potentially efficacious anti-infection remedies in the medieval pharmacopeia?

\subsection{Rational Drug Development? Patterns of Ingredient Usage in Medieval Leechbooks}

We cannot effectively answer the above questions with a small-scale approach to finding and testing infection remedies that look interesting: this would be laborious and doubtless lead us up many blind alleys. What we need instead is a top-down approach to analysing the data present in medical texts and predicting what sorts of remedies seem to be most promising: whether some ingredients were used repeatedly to treat symptoms that clearly suggest infection, and, more importantly, whether certain ingredients were repeatedly combined together to treat these symptoms. If such cocktails of ingredients exist, then these are where we must focus our research effort.

A small-scale analysis of the context of Bald's eyesalve within 'Bald's Leechbook' suggests this remedy was not simply thrown together using a random selection of ingredients that the compiler had to hand. We sought to find out how often the various ingredients present in the eyesalve co-occurred in other remedies in the same text. We therefore compared the frequency with which each possible pair of ingredients appeared together in a recipe with the frequencies with which ingredients appeared in any recipe, regardless of combination. In this manner, we were able to calculate the probability of observing $n$ recipes containing ingredients $A$ and $B$, if $A$ and $B$ were assigned randomly to remedies. Our methodology was to perform searches of the electronic text of 'Bald's Leechbook' held on the 'Dictionary of Old English Web Corpus $^{33}$ for each ingredient present in the eyesalve. We were aided here by two other carefully curated databases of Old English language, namely 'The Dictionary of

32 See note 8.

33 Antonette diPaolo Healey / John Price Wilkin / Xin Xiang, Dictionary of Old English Web Corpus. Toronto, Dictionary of Old English Project 2009, online: http://tapor.library.utoronto.ca/ doecorpus/ (last accessed 15/05/2019). 
Old English Plant Names' and 'A Thesaurus of Old English'. ${ }^{34}$ These allowed us to ensure that we included synonyms in our search, e. g. BIERBAUMER et al. give cipe, cipe-leac and ynne-leac for 'onion'. It also allowed us to exclude spurious results: e. g. a text search for the fragment leac returns not only Allium spp. containing this name element, but also leaccerse, which is translated by BIERBAUMER et al. as garlic mustard (Alliaria petiola) - a member of the Brassica family. ${ }^{35}$

Table 1 shows the number of recipes in 'Bald's Leechbook' containing each of the five ingredients in the eyesalve, the number of recipes we would expect to see containing each possible pair of ingredients if they are combined randomly, and the number of remedies that actually do contain each pair of ingredients - excluding the eyesalve itself. The Venn diagram in Figure 2 provides a pictorial representation of

Table 1: Calculating the probability that pairs of ingredients used in Bald's eyesalve were combined more often than expected under random chance.

\begin{tabular}{|c|c|c|c|c|c|c|}
\hline \multicolumn{2}{|c|}{$\begin{array}{l}\text { A) Occurrences of all } \\
\text { ingredients from the eyesalve } \\
\text { in Bald's Leechbook }\end{array}$} & \multicolumn{5}{|c|}{$\begin{array}{l}\text { B) Expected and observed co-occurrences (excluding the eyesalve } \\
\text { itself) }\end{array}$} \\
\hline \multirow[t]{2}{*}{ Ingredient } & \multirow[t]{2}{*}{ Remedies } & \multirow[t]{2}{*}{ Ingredient A } & \multirow[t]{2}{*}{ Ingredient B } & \multicolumn{2}{|c|}{$\begin{array}{l}\text { Remedies } \\
\text { with A \& B }\end{array}$} & \multirow[t]{2}{*}{ Probability } \\
\hline & & & & Exp. & Obs. & \\
\hline Copper vessel & 12 & Copper vessel & Garlic & 0 & 0 & \\
\hline Garlic & 14 & Copper vessel & Gall & 0 & 0 & \\
\hline Gall & 21 & Copper vessel & Other Allium spp. & 0 & 0 & \\
\hline Other Allium spp. & 25 & Copper vessel & Wine & 1 & 4 & 0.00125 \\
\hline Wine & 65 & Garlic & Gall & 0 & 0 & \\
\hline \multirow[t]{5}{*}{ Est. total recipes: } & 1493 & Garlic & Other Allium spp. & 0 & 4 & $<0.001$ \\
\hline & & Garlic & Wine & 1 & 0 & \\
\hline & & Gall & Other Allium spp. & 0 & 0 & \\
\hline & & Gall & Wine & 1 & 0 & \\
\hline & & $\begin{array}{l}\text { Other Allium } \\
\text { spp. }\end{array}$ & Wine & 1 & 1 & \\
\hline
\end{tabular}

34 Peter Bierbaumer / Hans SAUER / Helmut W. Klug / Ulrike KrischKE (eds.), Dictionary of Old English Plant Names, 2007-2017, online: http://oldenglish-plantnames.org (last accessed 15/05/ 2019); Jane Roberts / Christian KaY / Lynne Grundy, A Thesaurus of Old English, Glasgow, University of Glasgow 2015, online: oldenglishthesaurus.arts.gla.ac.uk (last accessed 15/05/2019). 35 BiERBAUMER et al. (note 34). 


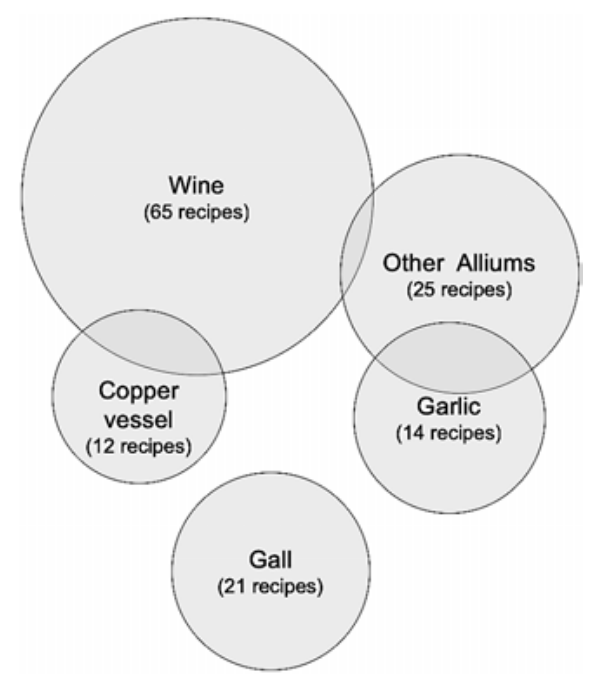

Figure 2: Venn Diagram showing co-occurrences of eyesalve ingredients elsewhere in 'Bald's Leechbook'. The size of each circle is proportional to the number of remedies containing each ingredient, and the size of each area of overlap is proportional to the number of remedies containing each pair of ingredients.

the frequencies of ingredient combination. Four remedies combine garlic with other Allium species, and four require the use of a copper alloy vessel and wine. Given the prevalence of each individual ingredient in the 'Leechbook', under the random allocation of ingredients to remedies we would expect to observe zero or one such remedy respectively. The probability of observing four such remedies under the assumption of random assortment is therefore quite low: using Fisher's Exact Test, the probability of four remedies including both garlic and another Allium species is less than one in one thousand, and the probability of four remedies containing both wine and a copper vessel by chance is one in eight hundred. A rule of thumb in science is to accept a probability of less than one in twenty as being unlikely to be due to chance; we suggest that these pairs of ingredients were deliberately put together.

The use of copper vessels is interesting, especially given that in our test of Bald's eyesalve, this was the one ingredient not required for antibacterial activity. All the remedies in 'Bald's Leechbook' that refer to copper alloys use this material for the vessel in which the remedy is prepared (as opposed to a direct ingredient), and of the twelve such remedies, nine are for eye complaints. Parallels are found elsewhere in medieval medicine, for example a remedy for blurred vision in a ninth/tenth-century Latin and Old Breton text held by the University of Leiden (MS Vossianus lat. f. 96A) contains a remedy that calls for the ingredients to be placed 
in a bronze box. ${ }^{36}$ Perhaps this was due to an observation that materials left in copper or copper alloy vessels were less likely to 'go off', as copper surfaces retard bacterial colonisation - or it could be due to some unknown magico-medical connection between copper and eye complaints, or to the placebo effect of receiving a medicine in fancy packaging. Even now, large numbers of people believe that generic drugs are not as effective as identical drugs supplied in branded packaging, and supplying placebo painkillers in branded packaging enhances the placebo effect. ${ }^{37}$ Finally, it is possible that a large copper vessel could leach sufficient copper into the eyesalve (Mike DrouT, personal communication) to further enhance the antibacterial effect, and that our failure to observe this was simply due to the much smaller surface area of brass we used to simulate the presence of the vessel.

Similar patterns of ingredient combinations are seen in other recipes used to treat infectious conditions in the medieval literature selected for preliminary analysis. For instance, throughout medical history various species of Plantago (in combination with vinegar or wine and other medicinal plants) are administered for a number of conditions, including wounds (and surgically induced wounds), skin infections, insect stings, oral conditions, abscesses in the gums, burns (caused by water or fire), nail infections, nosebleeds, digestive complaints, diarrhoea, liver problems, respiratory conditions (cough, throat infections), vomiting blood, kidney stones and blood in the urine. In the fifteenth-century Middle English 'Lylye of Medicynes' (Oxford, Bodleian Library MS Ashmole 1505), Plantago spp. often appear in recipes in co-occurrence with descriptions of cutaneous infections from the simple (the first sign of redness) to the severe (ulceration, purulence, and black crusts), including wounds, swellings, abscesses, lesions, carbuncles, pustules, and rashes. ${ }^{38}$ In these recipes, Plantago spp. is crushed (ground) and soaked or boiled in vinegar, wine or water, mixed with other medicinal plants and applied directly to the affected area. Due to its long history of use in traditional medicine, Plantago spp. is a popular candidate for laboratory studies investigating the efficacy of herbal remedies for the treatment of wounds or infection. In some of these studies, the species Plantago major and Plantago lanceolata have

36 Benjamin FrancKaERT, Santé et pratiques médicales des Bretons insulaires et continentaux du Haut Moyen Âge ( $\mathrm{V}-\mathrm{X}^{\mathrm{e}}$ siècles): revue de la littérature ouverte, analyse croisée des données historiques et archéologiques, Brest (Université de Bretagne occidentale, med. diss.) 2014, online: https://dumas.ccsd.cnrs.fr/dumas-01006406/document (last accessed 15/05/2019).

37 Sarah Colgan / Kate FaAsse / Leslie R. Martin / Melika H. Stephens / Andrew Grey / Keith J. PetRIE, Perceptions of Generic Medication in the General Population, Doctors and Pharmacists. A Systematic Review, in: BMJ Open 5 (2015), e008915; Kate FAASSE / Leslie R. MARTIN / Andrew GREY / Greg D. GAmBlE / Keith J. PETRIE, Impact of Brand or Generic Labeling on Medication Effectiveness and Side effects, in: Health Psychology 35 (2016), pp. 187-190.

38 Erin Connelly, A Case Study of Plantago in the Treatment of Infected Wounds in the Middle English Translation of Bernard of Gordon's Lilium medicinae, in: Erin CONNELLY / Stefanie KüNZEL (eds.), New Approaches to Disease, Disability, and Medicine in Medieval Europe, Oxford 2018, pp. 126-140. 
been associated with many beneficial properties, including antibiotic, antiviral, antioxidant, anti-inflammatory, anticancer, and hepatoprotective effects along with wound healing. ${ }^{39}$ Some researchers suggest that these species possess wound healing properties, ${ }^{40}$ or may be candidates for use in combination with conventional antibiotics or other medicinal plants in infection prevention. ${ }^{41}$ Many bioactive plant compounds are only active in freshly-crushed material (aucubin from Plantago spp. is an excellent example of this), and solvent extraction can capture less activity than lowtech extraction methods such as soaking in water (artemisinin from Artemisia spp. providing a high-profile example). The results of studies using dried leaves may therefore underestimate the antibacterial capacity of fresh whole-plant material.

Nettles (Urtica dioica / U. urens) also appear several times in medieval texts in connection with potentially infected wounds. Preliminary analysis of 'Bald's Leechbook', a tenth-century translation of the fourth-century 'Pseudo-Apuleius Herbarius' and works by later medieval practitioners, such as the fourteenth-century surgeon John Arderne,

39 Ricardo Gómez-Flores / Cesar L. CALDERon / Leonard William Scheibel / Patricia TAmez-GuerRa / Cristina Rodríguez-Padilla / Reyes Silvestre TAmez-GuerRa / Richard J. Weber, Immunoenhancing Properties of Plantago major Leaf Extract, in: Phytotherapy Research 14 (2000), pp. 617-622; Geir Hetland / Anne Berit C. Samuelsen / Martinus LøviK / Berit Smestad Paulsen / Ingeborg S. AAberge / E. C. Groeng / Terje E. Michaelsen, Protective Effect of Plantago major L. Pectin Polysaccharide Against Systemic Streptococcus pneumoniae Infection in Mice, in: Scandinavian Journal of Immunology 52 (2000), pp. 348-355; Lien-Chai CHIANG / Wen CHIANG / Mei-Yin CHANG / Chun-Ching Lin, In Vitro Cytotoxic, Antiviral and Immunomodulatory Effects of Plantago major and Plantago asiatica, in: The American Journal of Chinese Medicine 31 (2003), pp. 225-234; Lien-Chai CHIANG / Wen Chiang / Mei-Yin Chang / Lean-Teik Ng / Chun-Ching Lin, Antiviral Activity of Plantago major Extracts and Related Compounds in vitro, in: Antiviral Research 55 (2002), pp. 53-62; Idris TÜREL / Hanefi ÖZBEK / Remzi ERTEN / Ahmet Cihat ÖNER / Nureddin CENGIZ / Orhan YILMAZ, Hepatoprotective and Anti-Inflammatory Activities of Plantago major L., in: Indian Journal of Pharmacology 41 (2009), pp. 120-124; Suzanne NiLson / Fidji Gendron / Jody Bellegarde / Betty McKenna / Delores Louie / Geraldine MANSON / Harvey ALPHONSE, Preliminary Scientific Investigation of the Effectiveness of the Medicinal Plants Plantago major and Achillea millefolium Against the Bacteria Pseudomonas aeruginosa and Staphylococcus aureus in Partnership with Indigenous Elders, in: Global Journal of Research on Medicinal Plants \& Indigenous Medicine 3 (2014), pp. 402-415.

40 Ralph Gruppi Thomé / Hélio Batista Dos Santos / Fábio Vieira Dos Santos / Renato José Da SiLva Oliveira / Luis Fernando de Camargos / Mariana Nunes PEREIRA / Tamara Ribeiro LongatTi / Cássio Martins Souto / Carlaile Soares Franco / Raissa DE Oliveira Aquino SchÜFFnER / Rosy Iara Maciel DE AZAMBUja RiBEIRo, Evaluation of Healing Wound and Genotoxicity Potentials from Extracts Hydroalcoholic of Plantago major and Siparuna guianensis, in: Experimental Biology and Medicine 237 (2012), pp. 1379-1386; Ivan KovÁČ / Ján ĎURKÁČ / Martin HolLÝ / Katarína JAKUBČovÁ / Vlasta PeRŽELová / Pavel MuČajI / Emil ŠvajDlenka / František SABol / Jaroslav LEgáth / Jozef BeLÁK / Karel Smetana / Peter GÁL, Plantago lanceolata L. Water Extract Induces Transition of Fibroblasts into Myofibroblasts and Increases Tensile Strength of Healing Skin wounds, in: Journal of Pharmacy and Pharmacology 67 (2015), pp. 117-125, online (DOI): 10.1111/jphp.12316 (last accessed 15/05/2019).

41 Kemal Metinar / Oktay ÖZKAN / Seyyal AK, Antibacterial Effects of Ethanol and Acetone Extract of Plantago major L. on Gram Positive and Gram Negative Bacteria, in: Kafkas Üniversitesi Veteriner Fakültesi Dergisi 18 (2012), pp. 503-505; KARIMA / FARIDA / MiHouB (note 12). 
reveal a clear pattern of nettles being crushed and combined with salt and vinegar to make a salve for wounds likely to be infected: these include wounds described as foul or rotten, dog bites, frostbite, and surgical wounds. A small number of articles present results showing that extracts of nettle leaves and stems show antibacterial activity against various bacteria, including species that continue to cause chronic, antibioticresistant infections today, such as $S$. aureus, Klebsiella pneumoniae, Escherichia coli and Enterococcus faecalis. ${ }^{42}$ This is unsurprising as nettles contain a range of secondary metabolites known to have antibacterial activities, such as the flavonoids quercetin and kaempferol that are also significant bioactive components of Allium species. However, as with much research into Plantago spp. these results are based on solvent extracts of dried plant material and, as with most ethnopharmacological research, combinations of nettles with the salt and vinegar used by our pre-modern physicians have not been tested. As with Plantago, nettles are unlikely to trigger adverse effects when applied to the skin, or consumed: nettles are widely eaten as a vegetable and used to make beer, cheese, and shampoo. A combination of nettles with salt and vinegar both non-toxic substances known to have some bactericidal activity - could in theory lead to enhanced antibacterial activity of the three-part cocktail. The Ancientbiotics team is currently undertaking further research into nettles activity thanks to funding provided by the Royal Society APEX Award (Academies Partnership in Supporting Excellence in Cross-disciplinary Research Award). ${ }^{43}$

Our team has thus identified remedies containing plantains or nettles as useful focal groups of remedies which we would like to make in the lab and test for antimicrobial activity, and work is ongoing in this area. However, approaches that rely on our a priori knowledge of texts, ingredients and microbes to look for patterns radiating from a focal recipe, substance or symptom may have limited power. Going beyond this simple approach to attempt 'big data' analyses of medical texts requires working with yet another discipline: the field of data science can supply powerful analytical tools to find patterns of ingredient combination, and the mapping of groups of ingredients to symptoms, with no a priori assumptions about potential patterns or useful ingredients.

42 Nursel Dostbil / Sema Agaoglu / Suleyman Alemdar, The Antibacterial Activity of Common Nettle, in: Indian Veterinary Journal 82 (2005), pp. 492-494; Julia E. CHRUBASIK / Basil D. Roufogalis / Hildebert WaGner / Sigrun A. ChrubasiK, A Comprehensive Review on Nettle Effect and Efficacy Profiles, Part I: Herba Urticae, in: Phytomedicine 14 (2007), pp. 423-435; Amir MODARRESI-CHAHARDEHI / Darah IBRAhim / Shaida FaRIZA-Sulaiman / Leila MouSAVI, Screening Antimicrobial Activity of Various Extracts of Urtica dioica, in: Revista de Biología Tropical 60 (2012), pp. 1567-1576; Kais Kassim GHAIMA / Noor Makie HASHIM / Safaa Abdalrasool Ali, Antibacterial and Antioxidant Activities of Ethyl Acetate Extract of Nettle (Urtica dioica) and Dandelion (Taraxacum officinale), in: Journal of Applied Pharmaceutical Science 3 (2013), pp. 96-99, online (DOI): 10.7324/JAPS.2013.3518 (last accessed 15/05/ 2019).

43 "Nettles and Networks: New Ways to tackle Wound Infections." Principal Investigator: Dr Christina LEE, University of Nottingham. The Award runs from 2019 to 2021. 


\subsection{Looking to the Future: Datamining Medieval Texts for Antibiotic Discovery}

The success of the Bald's eyesalve pilot study and others, such as Tu YouYou's development of artemisinin (from Artemisia annua), a therapy for malaria derived from traditional herbal medical texts (awarded the Nobel Prize in Physiology or Medicine in 2015), have produced a series of questions relevant to the history of medicine and modern day research. Did medieval physicians follow a predictable rational method and how did they adapt and improve earlier remedies to use local ingredients, or to target different aetiologies? Where we see contingencies of different remedies for a condition, what conclusions can be drawn about the methodology of medieval practitioners? Finally, do ancientbiotic cocktails hold the key to discovering new natural compounds, or cocktails of compounds, that could form the basis of novel treatments for infection? Thus far research has been concentrated around single specific recipes from select medieval texts (e. g. 'Bald's Leechbook', 'Lylye of Medicynes') - a process which is limited by the availability and accessibility of medieval texts, as well as the constraints of researchers mining these texts by hand. Using digital technologies, specifically relational databases and network analysis from the field of data science, ${ }^{44}$ to conduct a large-scale survey of ingredients from multiple medieval texts may provide a foundation to build evidenced answers to such questions and unlock the medieval medicine cabinet.

This pipeline of data-driven exploration of texts, underpinned by qualitative knowledge from the arts and sciences with regard to manuscripts, cultural contexts and ingredients, will ultimately inform laboratory testing, with an aim to develop novel antibiotics. A small-scale pilot study in collaboration with a mathematician was performed to test the viability of this hypothesis. ${ }^{45}$ This study applied the tools of data science to the 'Lylye of Medicynes', as a base text, to analyse the interrelatedness and co-occurrence of the ingredients and relationship of the ingredients to

44 Réka AlBert / Albert-László BarabÁsI, Statistical Mechanics of Complex Networks, in: Reviews of Modern Physics 74 (2002), pp. 47-97; Mark E. J. NEwman, The Structure and Function of Complex Networks, in: SIAM Review 45 (2003), pp. 167-256; Sergey N. DoROGovTSEV / Alexander V. GolTSEv / José F. F. MENDES, Critical Phenomena in Complex Networks, in: Reviews of Modern Physics 80 (2008), pp. 1275-1335; Yong-Yeol AHn / Sebastian E. AHnERT / James P. BAGRow / Albert-László BARABÁSI, Flavor Network and the Principles of Food Pairing, in: Scientific Reports 1 (2011), p. 196, online (DOI): 10.1038/srep00196 (last accessed: 15/05/2019); Federico BoTTA / Charo DEL GENIO, Finding Network Communities Using Modularity Density, in: Journal of Statistical Mechanics (2016), online (DOI): 10.1088/1742-5468/2016/12/123402 (last accessed 15/05/2019).

45 Laboratory tests to complement the study are being analysed; for a preprint of the preliminary results of the datamining see Erin CoNNELLy / Charo I. DEL GenIo / Freya HARRISON, Datamining a medieval medical text reveals patterns in ingredient choice that reflect biological activity against the causative agents of specified infections, in: BioRxiv (16/07/2018), online (DOI): https://doi.org/ 10.1101/368779 (last accessed 15/05/2019). 
disease states, specifically infectious disease. This analysis suggests sets of ingredients that were repeatedly combined and used to treat specific infection symptoms: these are, we hypothesize, the sets of ingredients that are most likely to produce antibiotic effects when combined, and therefore those on which lab work should focus. This approach provides valuable data about potential ancientbiotic cocktails and the feasibility of a large-scale study involving multiple texts and a much larger dataset.

There are specific challenges to integrating medieval data with twenty-firstcentury digital technology, including medieval spelling and language variation, multiple synonyms for the same ingredient, translation of medieval ingredients into modern equivalents (many ingredients are ambiguous or have multiple possible interpretations), the variation within the modern system of botanical binomial nomenclature itself from the ongoing centuries-long process of classification, and avoiding the perils of retrospective diagnosis. The nascent pilot study serves as a model for the efficacy of the data pipeline hypothesis for a large-scale study, and it serves to work out solutions to these challenges, of which currently there is no established methodology. This insight into underlying patterns in medieval medical data revealed by modern technological methods may enable a move beyond testing individual recipes lifted from medieval texts to a process of creating new pharmaceuticals inspired by the ingredients of the past based on a system of quantitative measures of the likelihood of antibiotic activity when specific ingredients are combined.

\section{Approaches to Interdisciplinarity: Power and Pitfalls}

We conclude our chapter with an exploration of what we have learned from each other, and how we have had to think outside our usual disciplinary boundaries in order to make this project work.

\subsection{What Can We Learn and Achieve Through Interdisciplinary Working?}

Turning historical medical texts into a new drug discovery resource is only possible through dedicated interdisciplinary collaboration. It requires close working relationships, unity of conviction, good communication, digital accessibility and discoverability of data, and knowledge exchange between (a) experts in medieval medicine and manuscripts (for the analysis and translation of pre-modern texts), (b) experts in microbial pathogenicity and molecular microbiology, (c) experts in analytical and natural compound chemistry, and (d) experts in data science for the creation of 
databases and network visualizations, which reveal new patterns in medieval ingredient data. In the future, using this approach for comparative analyses of texts could also help us to explore how medieval physicians created and shared knowledge, and how their approaches varied across time and geography. In this way, we could better understand the medieval mind.

The sciences and humanities are often presented as diametric opposites; however, the Ancientbiotics collaboration suggests that interdisciplinary work can yield remarkable outcomes. As discussed in this chapter, interdisciplinary collaboration requires a willingness to step outside of the structures of one's own discipline and methodology in order to learn the skills and methodologies of another discipline. The scientists involved in the Ancientbiotics collaboration had to become familiar with the languages of the past (e. g. Old English, Middle English, Latin), as well as adjust a modern scientific worldview to differences in the way their predecessors thought about scientific principles (e. g. physicians of the past worked from an incorrect humoral understanding of disease). The medievalists and historians had to learn the methodologies of laboratory research and become familiar with principles of microbiology (e. g. biofilms, quorum sensing). With these shared understandings, it is easier to see the elements of medieval recipes which convey cultural and scientific merit and thus select viable candidates for testing.

\subsection{Impediments to Successful Interdisciplinary Research, and some Suggestions for Removing Them}

While 'interdisciplinary' is regarded ubiquitously as a positive attribute, collaborative efforts which unite disciplines that are traditionally regarded as diametric opposites (the arts and the sciences) are often considered high-risk by peer reviewers. ${ }^{46}$ The impediment is in creating an interdisciplinary proposal that speaks to the needs of reviewers from all disciplines, so that they each feel that their field has an adequate amount of focus. This is difficult within the space constraints of grants and because there is a need to keep everything accessible to everyone. It is possible that the main impediment with applying for funding involves the lack of training of peer reviewers in how to approach interdisciplinary grants. Perhaps the review process could benefit from more oversight by core funding body reviewers who can guide peer reviewers on how to approach the task (e. g. explicitly remind them that for an interdisciplinary grant application the level of detail and style of communication is necessarily different because it has to be understandable to people from different areas).

46 As we experienced during preparation of this chapter, which one professional vociferously refused to review. 
Furthermore, an impediment closely related to that of peer review, is resistance from within the disciplines to ideas that challenge traditional perspectives and collaborations that unite non-traditional elements, i. e. some academics believe that they must act as gatekeepers, which impedes movement across the disciplines as well as movement forward to meet common goals. However, we suggest that solving global problems, such as antimicrobial resistance, requires the application of global mindsets, or, stated another way, a solution may require the combined effort of individuals with diverse expertise working across disciplinary boundaries. Our preliminary results suggest that the outcome of such alliances can be greater than the sum of its parts. With further research in this spirit, it may be possible to show that the past could inform the future, and that the ancientbiotics of yesterday could have real implications for the antibiotics of today.

\section{Conclusions and Future Directions}

Relevance to multi-disciplinary concerns and wider societal issues is a current requirement for most academic research projects, especially for those in the humanities. At the "Making the Medieval Relevant" conference sponsored by the British Academy there was a range of international representatives from the fields of Economics, Microbiology, History, English, Archaeology, and Genetics, which demonstrates the multi-disciplinary significance of medieval topics, as well as the ability of medieval studies to shed light on both historical and present-day research when united with experts from the sciences, of which Bald's eyesalve is a successful example.

Many exciting discoveries remain to be made about medieval medical 'science'. Analysing and understanding medieval medicine and how it was practised will not just provide a window into the medieval mind. It could ultimately enhance ethnopharmacological research and - potentially - open new routes to drug discovery. To bring to fruition nascent work in this area, increased interdisciplinary participation and greater allocation of resources to arts/science collaborations that currently fall through the cracks of traditional disciplinary funding will be essential.

Acknowledgements: This chapter is one output of a large and diverse project undertaken by the wider Ancientbiotics consortium, which spans multiple disciplines, institutions and countries. We would therefore like to thank our colleagues Dr Christina LEE and Dr Steve DigGLE, who co-founded the team with us; Dr Aled Roberts, Dr Kendra Rumbaugh, Rebecca Gabrilska, Dr Lee Haines and Dr Álvaro ACOSTA SERRANO, who collaborated to design and conduct published and ongoing 
experimental work on Bald's eyesalve; Colman Ó Cathail, Jason Millington, Thorulf VARgSen, Gemma Lunn, Shajini Subhaskaran, Jenny LitTler, Callum PARSONS, and Navneet JANDU, who undertook student research projects to characterize ancientbiotics; Dr Stefanie KüNZEL for contributing expertise in Old English and Anglo-Saxon medicine; Dr James GuRNEY for his feedback on drafts of this chapter; Prof Dave BARRETT, Dr Cath ORTORI, Dr Jing Hu, and Dr Ricky CaIN who brought expertise in medicinal chemistry to the team; Dr Sheyda AzImI, Jessica Furner-Pardoe, Dr Blessing AnOnYe, Dr Meera UnNikrishnan, and Prof Julie BrucE for beginning work towards safety and efficacy testing of the eyesalve; Dr Charo DEL GENIO for expertise in datamining and network analysis; and Emma RAYNER and Louisa SHEPARD for their expertise in helping us to promote our work to the wider world. We are very grateful to Dr Conor KosTiCK and the attendees at the 2015 "Making the Medieval Relevant" meeting for their feedback on the presentations that formed the genesis of this chapter, to Mike DROUT and Benjamin FRANCKAERT for useful discussion and to the editors and two anonymous reviewers of this volume for their feedback on drafts of our chapter. Finally, for financial support, we thank the Universities of Nottingham, Warwick and Pennsylvania, the Schoenberg Institute for Manuscript Studies, University of Pennsylvania Libraries, the Council on Library and Information Resources, Diabetes UK, the APEX Award scheme, the Microbiology Society, the Medical Research Council Doctoral Training Programme in Interdisciplinary Biomedical Research and 66 very generous members of the public who gave to a crowdfunding campaign. 